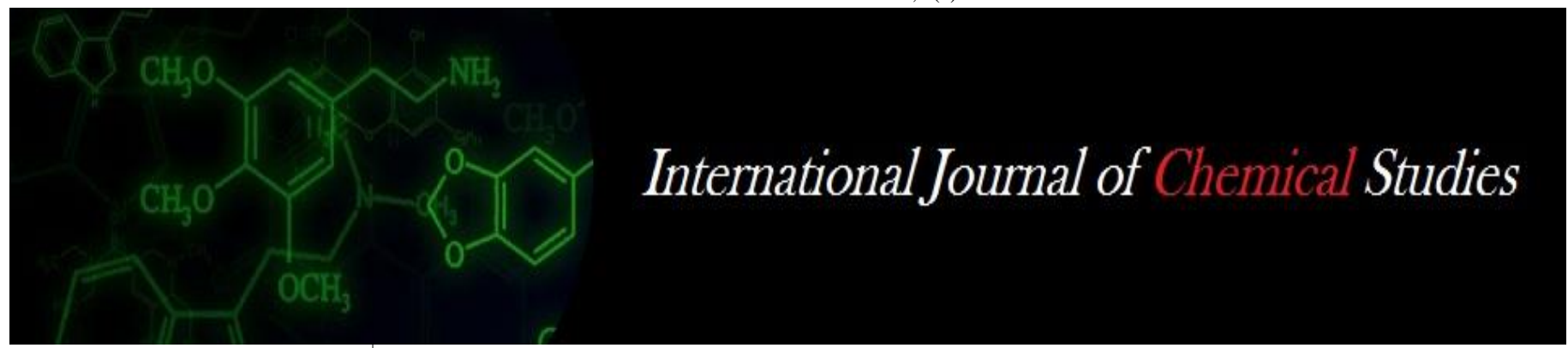

P-ISSN: 2349-8528

E-ISSN: 2321-4902

www.chemijournal.com

IJCS 2020; 8(4): 3059-3063

(C) 2020 IJCS

Received: 16-05-2020

Accepted: 18-06-2020

Anisha Shrivastava

Department of Agricultural

Microbiology, College of

Agriculture, Indira Gandhi

Krishi VishwaVidyalaya,

Raipur, Chhattisgarh, India

\section{Diptimayee Dash}

Department of Agricultural

Microbiology, College of

Agriculture, Indira Gandhi

Krishi VishwaVidyalaya,

Raipur, Chhattisgarh, India

Corresponding Author: Anisha Shrivastava Department of Agricultural Microbiology, College of Agriculture, Indira Gandhi Krishi VishwaVidyalaya, Raipur, Chhattisgarh, India

\section{Developing plant growth promoting rhizobacteria as bio-inoculants to enhance crop yield under stress condition}

\author{
Anisha Shrivastava and Diptimayee Dash
}

DOI: $\underline{\text { https://doi.org/10.22271/chemi.2020.v8.i4ak.10116 }}$

\begin{abstract}
Stresses are the prime factor for limiting agricultural productivity, during growth and development process plants inevitably experience a variety of abiotic stresses, such as drought, salt, and extreme temperature in which drought is most devastating abiotic stress. Recently searching for plant growth promoting rhizobacteria (PGPR) for sustainable crop production and proven to be an good alternative to chemical and to control abiotic stresses. The technique of growth promotion by PGPR that may be either direct or indirect effect on the plant productivity. Plants-microbe interaction is essential for the ecosystem. when stress level increases in environment, it becomes more essential to characterize and decipher plant-microbe association in relation to defense against environmental challenges. By isolating, characterizing and inoculating with effective bio-inoculants of rhizobium and Pseudomonas fluorescens can reduce abiotic stress in my crops and gives higher yield. Bio-inoculants help to cope up with adverse environment condition and providing stress free condition resultant increase the production and productivity of crop.
\end{abstract}

Keywords: Rhizobium, Pseudomonas fluorescens, plant growth promoting rhizobacteria (PGPR), abiotic stresses, bio-inoculants

\section{Introduction}

A thin layer of soil surrounding the plant root where majority of soil organism's predominance resides and roots influenced soil health as well as quality called as rhizosphere. Use of microorganisms as bio-inoculants aims at improving nutrient availability for plants. Rhizosphere contains a variety of environmentally-friendly sound bacteria which are beneficial for crop are called plant growth promoting rhizobacteria (PGPR). The majority of rhizobacteria present in the rhizosphere are thought to have direct consequence on plant growth and vigor. Rhizobium and Pseudomonas is a major bacteria which show symbiotic associated with many crop. Therefore using rhizobia as a soil inoculants or co-inoculates has shown to increase production of crops. Rhizobium are Gram Negative bacteria show plant microbe interaction and having capability to reduce atmospheric nitrogen in available form so that the plants can utilize it by the process of biological nitrogen fixation. Currently there is emerging demand to reduce the dependence on synthetic fertilizer as it is giving a bad impact on soil and animal health. Leguminous plant has difference from other plant because has the ability to fix nitrogen and done by plant microbe-interaction and help to cope up with various stress. Isolation of rhizobium, identification and characterization and using effective isolates as bio-inoculants can fix about $70 \%$ of nitrogen which reduces synthetic fertilizers use which leads to increase the soil heath, crop production and profit. Soil inoculants is inexpensive to all farmers which helps to increase the productivity of crop, recover the texture of soil and availability of nutrients. Evaluation of effectiveness of isolation rhizobia is essential for inoculums preparation. A brief review relevant to "Developing Plant growth promoting rhizobacteria as bio-inoculants to enhance crop yield under stress condition". has been described in this paper.

\section{Isolation of Plant Growth Promoting Rhizobacteria}

In this study of rhizobacteria, Rhizobium japonicum and pseudomonas fluorescence were isolated from the rhizosphere soil. 
Willems, (2006); Glick, (2012) ${ }^{[40,15]}$ stated that Hiltner was first who coined the term "rhizosphere" as the area of microbial activity around roots. Legume plant posses a unique ability to establish symbiosis with nitrogen-fixing bacteria of the family Rhizobiaceae. The bacteria belonging to the various genera Rhizobium, Bradyrhizobium, Allorhizobium, Pseudomonas, Erwinia, Flavobacterium, Rinorhizobium, Mesorhizobium Azospirillium, Azotobacter, Klebsiella which are collectively referred to as "rhizobia", are able to form nodules on their host plants inside of which they fix-nitrogen. Rao et al. (1999) Describes that the isolation of fluorescent Pseudomonads from the rhizoplane and rhizosphere of crop can be done. The King's medium B (KMB) was used to isolate P. fluorescens from the processed sample in the flask (King et al., 1954) ${ }^{[19]}$ as described by (Vidhyasekaran and Rabindran., 1996) ${ }^{[39]}$.

(Kings et al., 1954) [19] Reported that isolation of $\mathrm{P}$. fluorescens was made from rhizosphere of different field grown crops such as rice, maize, cotton, groundnut, sorghum, soybean, jowar, pigeonpea, bajara, black gram, chickpea and sunflower at Vidarbha and Konkan regions. King's B medium, a selective one was used for the isolation.

(Belkar, Y.K.) ${ }^{[7]}$ Study that P. fluorescens isolated from the rhizosphere of different crops from Vidarbha and Konkan regions were tested for their plant growth promoting and antagonistic potential.

Ali, S.Z., et al., (2014) ${ }^{[4]}$. Reported the isolation of rhizobium and pseudomonas from sixteen soil samples (non-rhizosphere and rhizosphere) were collected from different ecosystems covering arid, semi-arid and sub-humid zones. plants were uprooted, bulk soil was removed by gently shaking the plants and the rhizosphere soil was collected by dipping the roots in sterile normal saline followed by shaking for $30 \mathrm{~min}$. The soil suspension was serially diluted and appropriate dilutions were spread plated on YEMA and solid King's B medium. The plates were incubated at $28 \pm 2{ }^{\circ} \mathrm{C}$ rhizobium and fluorescent colonies were selected for further studies.

Sober6n-Chavez (1989) and Naijera and Jarvis et al. (1989) $[34,16]$ Both groups reported that when complemented with a sym plasmid, these isolates were able to establish an effective symbiosis with the host plant as determined by the plasmid. The isolation of non-symbiotic Rhizobium strains from soil has been described by Sober6n-Chavez (1989) and Naijera and Jarvis et al. (1989) ${ }^{[34,16]}$. isolated strains from soil that are chromosomally similar to R. leguminosarum.

Segovia, et al., (1991) [35] Reported that the isolation of nonsymbiotic bacteria by using growth on selective media, growth at specific temperatures, and intrinsic antibiotic resistances as selection criteria. The genetic relatedness of the nonsymbiotic isolates to different Rhizobium strains was determined by multilocus enzyme electrophoresis (MLEE) and corroborated by restriction fragment length polymorphism (RFLP) analysis of the rRNA operons.

\section{Benefits of Rhizobium and Pseudomonas}

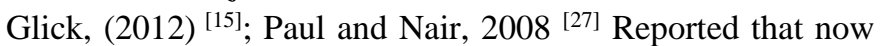
the alternatives and emerging technologies used to solve stress problem is naturally occurring plant growth promoting rhizobacteria (PGPR). There are number of reports that show the effectiveness of PGPR for enhancing plant growth and development

Inoculation of plants with Rhizobium can improved soil fertility and reduce the production cost of next crop through reduced input in the form of nitrogen fertilizers and which also minimize hazard effects of fertilizers on human, soil and environmental health (Mia and Shamsudin, 2010) ${ }^{[25] .}$

Pseudomonas fluorescens as Plant Growth Regulator and Phosphate Solubilizer Indole-3-acetic acid (IAA) is a phytohormone which is known to be involved in root initiation, cell division and cell enlargement. They promote plant growth by secreting auxins, gibberellins and cytokinins. The intrinstic ability of high level of IAA production by fluorescent Pseudomonads is a general characteristic. This bacterial IAA plays a major role in the development of host plant root systems. Phosphate solubilization occurs from carboxlic acids synthesized and released by microorganisms described Pseudomonas species as potent phosphate solubilizers.

There are many beneficial aspect of exploitation of Rhizobium in agricultural practice that the excessive use of chemicals to control plant diseases lead to groundwater contamination, development of resistant races of pathogen, human health hazardous and environmental detrimental (Akhar et al., 2009) ${ }^{[2]}$.

Martinez Romero, (2003) [22]; Sudhakar et al., (2000) [36]; observed that Root nodulation in legumes is a key determinant of plant growth and productivity because it provides biological nitrogen $(\mathrm{N})$ fixation through symbiosis with rhizobacteria. This symbiotic relationship reduces the requirements for nitrogenous fertilizers during the growth of leguminous crops and also enrich the soil with nitrogen.

The use of biological control agents as an alternative to fungicides is increasing rapidly in the present day agriculture due to the deleterious effects of chemical pesticides. Members of the genus Pseudomonas and Trichoderma have long been known for their potential to reduce the plant disease caused by fungal pathogens and they have gained considerable importance as potential antagonistic microorganisms (Pant and Mukhopadhyay, 2001).

Plant growth promoting rhizobacteria (PGPR) are a heterogeneous group of bacteria that are found in the rhizosphere and rhizoplane which can improve plant growth. Pseudomonas spp. is one of the most promising groups of PGPR which can control plant pathogenic microbes in the soil (O'Sullivan and O'Gara, 1992) ${ }^{[26]}$.

(Gaur et al., 2004) reported that Fluorescent Pseudomonas is uniquely capable of synthesizing many of these antibiotics, not only to enhance its own fitness but also to help in the maintenance of soil health and bioprotection of crops from pathogens Biological control using PGPR from the genus Pseudomonas is an effective substitute for chemical pesticides to suppress plant diseases (Compant et al., 2005)

Compant S, Duffy B, Nowak J, Clement C, Barka EA. Use of plant growth-promoting bacteria for biocontrol of plant diseases: Principles, mechanism of action and future prospects. Mini review. Appl. Environ. Microbiol. 2005; 71(9):4951-4959

Deshwal et al., (2011) ${ }^{[13]}$ reported that Biological nitrogen fixation (BNF) is the process responsible for the reduction of $\mathrm{N}_{2}$ to ammonia $\left(\mathrm{NH}_{3}\right)$ which is the main source of $\mathrm{N}$ in nature Nutrient enrichment of soils by nitrogen-fixing symbiotic bacteria present in legumes has been known for centuries. Scientific demonstration of this symbiosis was started in the 19th century and it established the facts that bacteria present in nodules on, legume roots are responsible for fixing atmospheric nitrogen. Rhizobium inoculants significantly improve yield in many leguminous crops and can minimize the use of synthetic fertilizer which is rather expensive and deteriorates soil properties. 
Observed that the bacterial infection thread allows rhizobia penetrating deep into the dividing cellular profile resulting in a new organ, the N-fixing 'nodule,' housing infected rhizobia replicating within nodule cells). Inside infected cells, rhizobia are encapsulated with a plant-derived membrane forming the facultative organelle, the symbiosome. The movement of nutrients is strictly controlled by the symbiosome plant on from bacteria and regulates rhizobial activity and persistence. The symbiosis is facultative and initiated by nitrogen starvation of the host plant

Jordan, (1984) stated that Rhizobia are soil bacteria that fix N2 (diazotroph) after becoming established inside root nodules of legumes (Fabaceae). There are several different genera of Rhizobia, all of them belong to the Rhizobiales, a probably-monophyletic group of protobacteria and they are soil bacteria characterized by their unique ability to infect root hairs of legumes and induce effective N2fixing nodules to form on the roots. Unlike many other soil microorganisms, Rhizobia produce no spores and they are rod shaped, aerobic and motile.

Zahir et al. (2008) ${ }^{[43]}$. Lim and Kim (2013) ${ }^{[21]}$ ) it, is reported that IAA producing PGPR like pseudomonas fluorescence enhanced the nutrients uptake through modulating the root architecture in the drought-stressed soil. It also reported that Bacteria are capable of producing ACC-deaminase, which can mitigate the adverse impacts of drought stress by decreasing the ethylene levels. Bacterial 1-aminocyclopropane-1carboxylate (ACC) deaminase activity not only assimilates nitrogenous nutrients by breaking down the ethylene precursor ACC but also prevents the host plant from adverse effects of stress ethylene under biotic and abiotic stress conditions.

\section{Rhizobium and Pseudomonas in mitigating abiotic stress}

Bohnert, H.J et al. (1995) ${ }^{[9]}$ reported that yield loss in crops is due to abiotic stresses are more than $50 \%$. Plants inevitably experience a variety of abiotic stresses during their growth and development process, such as drought, salt, and extreme temperature.

Boyer (1982), Bohnert, H.J et al. (1995) [9] reported that accessibility, of protein for the necessitous sector of society requires at an affordable price because the soybean contains high-quality protein which is advantageous for health. For the same purpose need for high productivity of soybean but loss happens due to many reasons like abiotic and biotic stress It was reported that yield loss in crops is due to abiotic stresses are more than $50 \%$. Plants inevitably experience a variety of abiotic stresses during their growth and development process, such as drought, salt, and extreme temperature.

These stressors affect the plant growth and development in one way or another. For example, in water-limited conditions, reduction in initial plant growth decreases the size and number of cells in plant leaf (Aguirrezabal et al., 2006) ${ }^{[1]}$.

Elsevier GmbH Vurukonda, (2015) S.S.K.P., (2016) [14] reported drought is major stress Strategies like Plant growthpromoting rhizobacteria (PGPR) could play a significant role in the alleviation of drought stress in plants. These beneficial microorganisms colonize the rhizosphere/endo-rhizosphere of plants and impart drought tolerance by producing exopolysaccharides (EPS), phytohormones, 1aminocyclopropane1-carboxylate (ACC) deaminase, volatile compounds, inducing accumulation of osmolytes, antioxidants, upregulation or downregulation of stressresponsive genes and alteration in root morphology in the acquisition of drought tolerance. Induced Systemic Tolerance
(IST) was coined for physical and chemical changes induced by microorganisms in plants which results in enhanced tolerance to drought stresses. PGPR helps plants to cope with different biotic and abiotic stress.

Cindy et al. (2002) ${ }^{[10]}$. Observed that understanding of rhizospheric-interactions is very important to increase the resilience of the agroecosystem against climate change and to maximize crop productivity under harsh conditions (drought, salinity, heavy metal pollution, and temperature stress). Endophytic beneficial bacteria promote plant growth while residing within the plant body where they get a protective and suitable environment for better growth compared to bacteria that interact with those plants epiphytically. Endophytes, colonize internal plant tissues instead of external surfaces (as in rhizobacteria) and promote plant growth and development in the same way as rhizobacteria through direct (i.e. nutrient availability) and indirect mechanisms (i.e. resistance against diseases). It is well documented that these endophytic bacteria can enhance plant growth under drought stress.

Abiotic stresses such as drought, flooding, waterlogging, high salinity, extreme temperatures, mineral deficiency and heavy metals result in lowered productivity and yield of the crop to less than $60 \%$.

\section{Use of PGPR as bioinoculants in enhancement of yield under stress}

Reported that several microbes promote plant growth, and many microbial products that stimulate plant growth have been marketed. In this review we restrict ourselves to bacteria that are derived from and exert this effect on the root. Such bacteria are generally designated as PGPR (plant-growthpromoting rhizobacteria). The term PGPR was first defined by Kloepper and Scroth (1978), to describe soil bacteria that colonize the roots of plants and promote plant growth.

Shahzad et al. (2013) ${ }^{[29]}$ Whipps, (2001) ${ }^{[41]}$; Bloemberg and Lugtenberg, (2001) ${ }^{[8]}$. Reported that application of bacterial inoculants such as PGPR and organic amendments (e.g. compost) has recently been emerged as a useful tool to improve plant growth and soil quality in various soil conditions. Microbial communities are abundantly present in rhizosphere or areas under the influence of the root and its close vicinity. Indirect effects are related to the production of metabolites such as antibiotics. Direct effects are dependent on the production of plant growth regulators, improvement in plant nutrients uptake, or promote induce systemic resistance (ISR) of the plant.

Jha and Saraf, (2015) Observed that Microbial inoculant as, biofertilizers reduce the need for chemical fertilizers by improving the soil fertility status through different soil processes i.e. mineralization, decomposition, and the release/storage of essential, nutrients, with no negative influence on the environment. PGPR performs the process of associative N2-fixation legume crops.

(Mia and Shamsudin, 2010) [25] Observed that inoculation plants and soil with Rhizobium can improved soil fertility and reduce the production cost of next crop through reduced input in the form of nitrogen fertilizers and which also minimize hazard effects of fertilizers on human, soil and environmental health

Reorted that use of bio inoculants (plant growth-promoting rhizobacteria) has been of great help in combating this abiotic stress.

Shahzad et al. (2013) ${ }^{[29]}$ Whipps, (2001) ${ }^{[41]}$; Reported that application of bacterial inoculants such as PGPR and organic amendments (e.g. compost) has recently been emerged as a 
useful tool to improve plant growth and soil quality in various soil conditions. Microbial communities are abundantly present in rhizosphere or areas under the influence of the root and its close vicinity. Indirect effects are related to the production of metabolites such as antibiotics. Direct effects are dependent on the production of plant growth regulators, improvement in plant nutrients uptake, or promote induce systemic resistance (ISR) of the plant.

Sheng and He, (2006) ${ }^{[31]}$ Observed that Microbial inoculant as, biofertilizers reduce the need for chemical fertilizers by improving the soil fertility status through different soil processes i.e. mineralization, decomposition, and the release/storage of essential, nutrients, with no negative influence on the environment. PGPR performs the process of associative N2-fixation legume crops.

Singh and Trivedi, (2017) [33] Reported that microbial inoculation to combat drought stress Rhizobacterial inoculation to ameliorate water-deficit stress in plants is a, growing field of interest. The beneficial effects of these rhizobacteria on plant growth can be direct or indirect first clear indication of improved plant growth and biological control of root pathogens was from seed bacterization with Pseudomonas rhizobacteria strains. Kloepper et al. (1980) coined the term PGPR to include 16 bacteria inhabiting root and rhizosphere soil, which have the ability to increase plant growth.

PGPR is beneficial to soil bacteria which improves plant growth and development and colonizes the narrow zone of plant roots (rhizosphere). PGPR is a heterogeneous group of bacteria that must be able to (i) colonize the plant roots, (ii) compete with other microbes that have similar potential, and (iii) plant-growth-promoting and protecting activities include the production of phytohormones (e.g., IAA, gibberellins, ethylene, abscisic acid), ACC-deaminase, volatile organic compounds, nutrient acquisition, exopolysaccharides (EPS), biofilm formation and induced systemic resistance (ISR). Kaushal and Wani, (2016) ${ }^{[16]}$; Singh and Trivedi, (2017) ${ }^{[33]}$; Saikia et al. (2018) Verma et al. (2016) [38]; Saikia et al. (2018).

Alori et al. (2017) ${ }^{[5]}$ Reported that during root colonization, some PGPR enhance the availability of nutrients in the rhizosphere to enhance successful adaptation and survival of plants will gear toward ensuring a sustainable crop yield and improvement of soil fertility and structure. This is a good approach to stress management. These microbes through deaminase enzyme production, nodulation, and other physiological activities at the rhizosphere help the plants tolerate stress.

\section{Conclusion}

Using low cost, environment-friendly microbial inoculation could be a useful approach to overcome the negative impacts of abiotic stress and lead to improved crop yield under stress. The mechanism of drought tolerance in rhizobacteria and genes responsible for these mechanisms could be further research prospects. Plant-microbe interaction to mitigate drought tolerance at the genetic, molecular, and biochemical levels are vibrant issues to be addressed in future studies PGPR may enhance the plant growth and yield of the several crops. Despite them, it can enhance the quality of crop production and thus overall improved yield without deteriorating the soil and environmental condition. Use of efficient soil and rhizome-microorganisms under the soilplant environmental system act as an eco-friendly, economic, and sustainable productivity of the agricultural system.

\section{References}

1. Aguirrezabal L, Sandrine BC, Amandine RJ, Myriam D, Sarah JC, Christine G et al. Plasticity to soil water deficit in Arabidopsis thaliana: dissection of leaf development into underlying growth dynamic and cellular variables reveals invisible phenotypes. Plant Cell, 2006.

2. Aktar MW, Sengupta D, Chowdhury A. Impact of pesticides use in agriculture: their benefits and hazards. Interdiscip. Toxicol. 2009; 2(1):1-12.

3. Ali N. Soybean processing and utilization. In: Singh G (Ed). The soybean: botany, production and uses. UK: CAB International Press, 2010, 345-62

4. Ali SZ, Sandhya V, Rao LV. Isolation and characterization of drought-tolerant ACC deaminase and exopolysaccharide-producing fluorescent Pseudomonas sp. Annals of microbiology. 2014; 64(2):493-502.

5. Alori ET, Glick BR, Babalola OO. Microbial phosphorus solubilization and its potential for use in sustainable agriculture. Front Microbiol. 2017b; 8:971. https://doi.org/10.3389/fmicb.2017.00971

6. Barber DA, Martin JK. The release of organic substances by cereal roots into soil. New Phytologist. 1976; 76:6980.

7. Belkar YK, Gade RM. Biochemical characterization and growth promotion activities of Pseudomonas fluorescens. J Plant Dis. Sci. 2012; 7(2):170-174.

8. Bloemberg GV, Lugtenberg BJJ. Molecular basis of plant growth promotion and biocontrol by rhizobacteria. Curr. Opinion. Plant. Biol. 2001; 4:343-350

9. Bohnert HJ, Nelson DE, Jensen RG. Adaptations to environmental stresses. Plant. Cell. 1995; 7:1099-1111. [CrossRef] [PubMed]t zone. Crit. Rev. Microbiol. 1995; 36:232-244. [CrossRef]

10. Cindy L, J Vangronsveld, F Porteous, ERB Moore, S Taghavi, M Mezgeay et al. Endophytic bacteria and their potential applications. Critical Reviws in Plant Sciences, 2002.

11. Conrath U, GJ Beckers, V Flors, P Garcia-Agustin, G Jakab et al. Priming: getting ready for battle. Molecular Plant-Microbe Interactions. 2006; 19:1062-1071

12. Deshwal VK, K Vig, DM Amisha, $P$ Yadav, D Bhattacharya, M Verma et al. Synergistic effects of the inoculation with plant growth-promoting Rhizobium and Pseudomonas on the performance of Mucuna. Ann. Forestry. 2011; 19:13-20.

13. Dimkpa C, T Weinand, F Asch. Plantrhizobacteria interactions alleviate abiotic stress conditions. Plant Cell Environment. 2009; 32: 1682-1694.

14. Elsevier GmbH. All rights reserved Vurukonda, S.S.K.P., Vardharajula, S., Shrivastava, M. and SkZ, A., 2016. Enhancement of drought stress tolerance in crops by plant growth promoting rhizobacteria. Microbiological research. 2016; 184:13-24

15. Glick BR. Review article plant growth-promoting bacteria: mechanisms and applications. Scientifica. Article ID 963401. Hindawi Publishing Corporation, 2012; 15. http://dx.doi.org/10.6064/2012/963401

16. Jarvis BDW, LJH Ward, EA Slade. Expression by soil bacteria of nodulation genes from Rhizobium leguminosarum biovar trifolii. Appl. Environ. Microbiol. 1989; 55:1426-1434.

17. Jones DL, Hodge A, Kuzyakov Y. New Phytol. 2004; 163:459-480.

18. Kaushal M, SP Wani. Agriculture, rhizobacterial plant interactions: Strategies ensuring plant growth promotion 
under drought and salinity stress. Agriculture Ecosystem and Environemnt. 2016; 231:68-78

19. King EO, MK Ward, DE Raney. Two simple media for the demonstration of pyocenin and fluorescin. J Lab. Clin. Med. 1954; 44:301-307.

20. Latef AA, Jan S, Abd-Allah EF, Rashid B, John R, Ahmad P et al. Soybean under abiotic stress: proteomic approach. Plant-Environment Interaction: Responses and Approaches to Mitigate Stress, 2016.

21. Lim JH, SD Kim. Induction of drought stress resistance by multifunctional PGPR Bacillus licheniformis K11 in pepper. Plant Pathology Journal. 2013; 29:201-208.

22. Martínez-Romero E. Diversity of Rhizobium-Phaseolus vulgaris symbiosis: overview and perspectives. Plant Soil. 2003; 252:11-23

23. Masciarelli O, Llanes A, Luna V. Anew PGPR coinoculatedwith Bradyrhizobium japonicum enhances soybean nodulation. Microbiol Res. 2014; 169:609-615.

24. Meera T, Balabaskar P. Isolation and characterization of Pseudomonas fluorescens from rice fields. International Journal of Food, Agriculture and Veterinary Sciences. 2012; 2(1):113-120

25. Mia MAB, Shamsuddin ZH. Rhizobium as a crop enhancer and biofertilizer for increased cereal production. African Journal of Biotechnology. 2010; 9(37):60016009.

26. O'Sullivan DJ, O'Gara F. Traits of fluorescent Pseudomonas spp. involved in suppression of plant root pathogen. Microbiol. Rev. 1992; 56:662-626.

27. Paul D, Nair S. Stress adaptations in a plant growth promoting rhizobacterium (PGPR) with increasing salinity in the coastal agricultural soils. J Basic Microbiol. 2008; 48:378-384.

28. Roy RN, A Finck, GJ Blair, HLS Tandon. Plant nutrition for food security. A guide for integrated nutrient management. In Fertilizer and plant nutrition bulletin. Food and agriculture organization of the United Nations, Rome, 2006.

29. Shahzad SM, Arif MS, Riaz M, Iqbal Z, Ashraf M. PGPR with varied ACC deaminase activity induced different growth and yield response in maize (Zea mays L.) under fertilized conditions. Eur. J. Soil Biol. 2013; 57:27-34.

30. Sahin FC, IR Akmakc, F Kantar. Sugar beet and barley yields inrelation to inoculation with N2-fixing and phosphate solubilizing bacteria. Plant and Soil. 2004; 265:123-12

31. Sheng XF, LY He. Solubilization of potassium bearing minerals by a wild type strain of Bacillus edaphicus and its mutants and increased potassium uptake by wheat. Canadian Journal of Microbiology. 2006; 52:66-72.

32. Sheng XF, WY Huang. Mechanism of potassium release from feldspar affected by the strain NBT of silicate bacterium. Acta Pedologica Sinica. 2002; 39:863-871.

33. Singh BK, P Trivedi. Microbiome and the future for food and nutrient security. Microbia Biotechnology. 2017; 10:50-53

34. Sober6n-Chavez G, R Najera. Isolation from soil of Rhizobium leguminosarum lacking symbiotic information. Can. J Microbiol. 1989; 35:464-468.

35. Segovia LORENZO, Piñero D, Palacios R, MartinezRomero E. Genetic structure of a soil population of nonsymbiotic Rhizobium leguminosarum. Applied and Environmental Microbiology. 1991; 57(2):426-433.

36. Sudhakar P, Chattopadhyay GN, Gangwar SK, Ghosh JK. Effect of foliar application of Azotobacter,
Azospirillum and Beijerinckia on leaf yield and quality of mulberry (Morus alba). J Agric Sci. 2000; 134:227-234.

37. Ohyama T, Minagawa R, Ishikawa S, Yamamoto M, Hung NVP, Ohtake N et al. soybean seed production and nitrogen nutrition, in: j.e. board (ed), A Comprehensive Survey of International Soybean Research - Genetics, Physiology, Agronomy and Nitrogen Relationships. InTech, Croatia, 2013, 115-157.

38. Verma P, R Saxena, Tomar. Rhizobacteria: A promising tool for drought tolerance in crop plants. International Journal of Pahrma and Bio Science, 2016. www.researchgate.netpublication/301683349.

39. Vidhyasekaran P, Rabindran R. Development of a formulation of Pseudomonas fluorescens PfALR2 for management of rice sheath blight. Crop Prot. 1996; 15(8):715-721.

40. Willems A. The taxonomy of rhizobia: An overview. Plant Soil. 2006; 287:3-14

41. Whipps JM. Microbial interactions and biocontrol in the rhizosphere. J Experiment. Bot. 2001; 52:487-511.

42. Yang J, JW Kloepper, CM Ryu. Rhizosphere bacteria help plants tolerate abiotic stress. Trends in Plant Science, 2009; 14:1-4.

43. Zahir ZA, A Munir, HN Asghar, B Shaharoona, M Arshad. Effectiveness of rhizobacteria containing ACC deaminase for growth promotion of peas (Pisum sativum) under drought conditions. Journal of Microbiology and Biotechnology. 2008; 18:958-963. 